\title{
A Case Series of Fetal Valproate Syndrome in the Republic of Crimea
}

\author{
Olga Nikolaevna Rybalko ${ }^{1} \quad$ Nikolai Nikolaevich Kaladze ${ }^{1}$ \\ ${ }^{1}$ Department of Pediatrics, Physiotherapy and Health Resorts, S.I. \\ Georgievsky Medical Academy, V.I. Vernadsky Crimean Federal \\ University, Simferopol, Crimea, Russia \\ 2Department of Public Health, S.I. Georgievsky Medical Academy, \\ V.I. Vernadsky Crimean Federal University, Simferopol, Crimea, \\ Russia \\ ${ }^{3}$ Neurology Unit, Department of Medicine, Universiti Kebangsaan \\ Malaysia Medical Centre, Kuala Lumpur, Malaysia
}

Irina Alexandrovna Sukhareva² Ching Soong Khoo³

\author{
Address for correspondence Ching Soong Khoo, MRCP (UK), \\ Jalan Yaacob Latif, Bandar Tun Razak, 56000 Cheras, Kuala Lumpur, \\ Malaysia (e-mail: chingsoongkhoo@gmail.com).
}

J Neurosci Rural Pract 2019;10:700-702

\author{
Abstract \\ Keywords \\ - fetal valproate \\ syndrome \\ - antiepileptic drug \\ - valproic acid \\ - pregnancy
}

Valproic acid or valproate is a well-recognized potent teratogen. Antenatal exposure to this drug can cause fetal valproate syndrome (FVS), which is a constellation of distinctive dysmorphic features and congenital malformations. Despite an abundance of reports and registries about this syndrome, there is lack of information from Russia, in particular, the Republic of Crimea. We herein describe two cases of FVS from our registry.

\section{Introduction}

Valproic acid (VPA) is commonly prescribed in patients with epilepsy because of its broad spectrum of antiepileptic efficacy. Its anticonvulsant effects are believed to be related to blockade of voltage-gated sodium channels and elevated brain concentrations of gamma-aminobutyric acid. ${ }^{1}$ In view of its ability to cross the blood-placental barrier, VPA use during pregnancy may cause fetal valproate syndrome (FVS), which is characterized by distinctive facial dysmorphism, congenital anomalies, and neurodevelopmental delay.

In Europe, FVS was reported to have a significant annual decrease by $27.5 \% .^{2}$ It might be due to increasing awareness of prescribing VPA in childbearing or pregnant women, or underreporting and underrecognizing.

Data from Russia on FVS are scarce. Crimea, as part of Russia, is a place of exceptional ethnic diversity. It is thus worthwhile describing the clinical features of FVS from the Crimean registry.

\section{Case History}

\section{Case 1}

The first case was a 10-day-old female neonate born to nonconsanguineous parents. Her mother had been taking VPA for epilepsy for almost 11 years and was on a daily dose of $1,200 \mathrm{mg}$ throughout her pregnancy. She took folate at $400 \mathrm{mg}$ concurrently. The infant was born at full term.

She had dysmorphic facial features with a high and broad forehead; epicanthic folds; thin, arched, and wide-spaced eyebrows; a small, upturned nose with a wide nasal bridge; a long, shallow philtrum; a thick lower lip, low-set ears, small mouth, and eyebrow hair loss; and hemangiomas on the upper lip and right superior eyelid (-Fig. 1). She had broad hands and feet; bilateral camptodactyly and clubbed feet ( - Fig. 2). On examination, her chest was barrel-shaped with a short neck. Mild systolic cardiac murmurs were auscultated.

Her brain magnetic resonance imaging (MRI) revealed multilobar hypoplasia, porencephalic cysts, and corpus callosum agenesis. Echocardiogram (ECHO) detected a ventricular septal defect. Abdominal ultrasound was normal. Electroencephalogram revealed epileptic discharges from the right occipital region.

\section{Case 2}

A 3-month-old female infant was brought to the tertiary hospital with myotonia, psychomotor delay, and malnutrition. She was born to nonconsanguineous parents. Her mother had been taking VPA for the past 15 years and was on a daily 


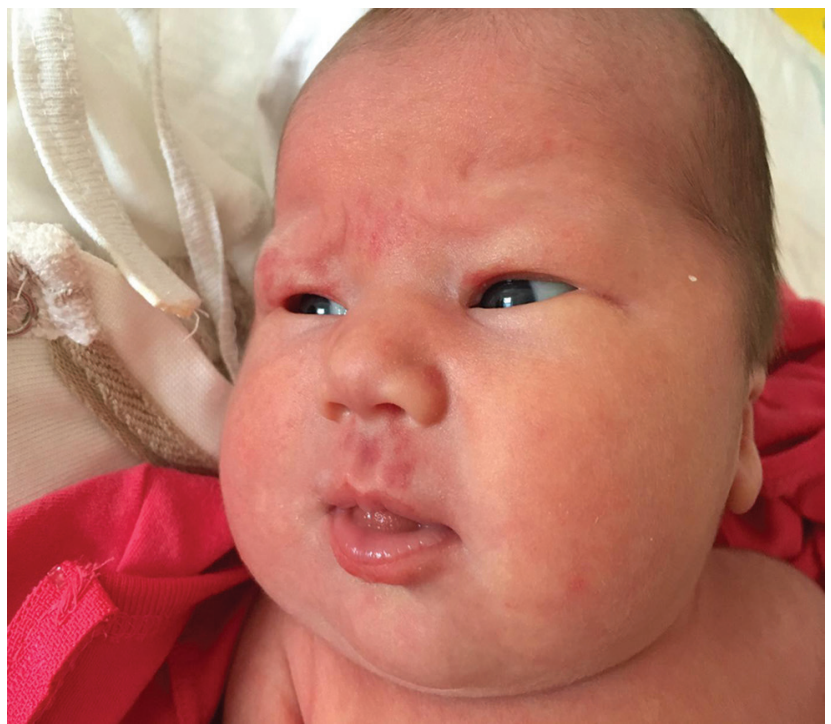

Fig. 1 Dysmorphic features of the first case.

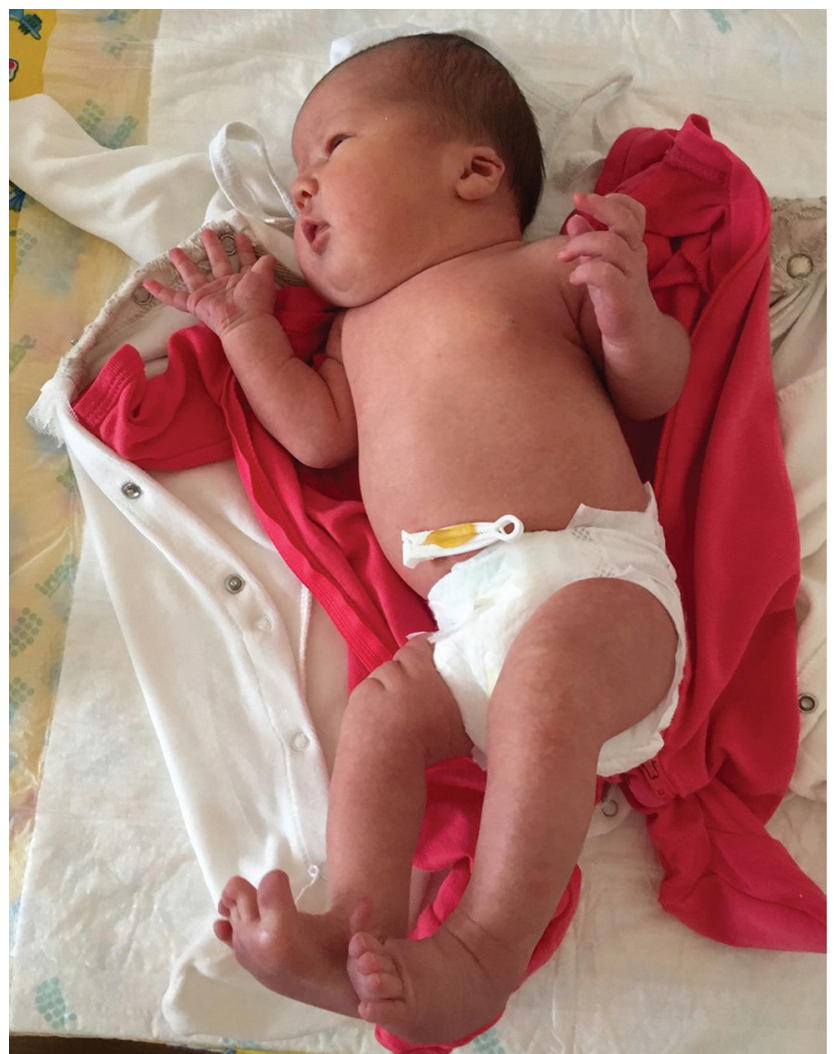

Fig. 2 Short neck and barrel-shaped chest wall in the first case.

dose of $800 \mathrm{mg}$ throughout her pregnancy. She was compliant with folate at $800 \mathrm{mg}$ daily. Polyhydramnios was detected at 31 weeks of gestation. The infant was born at full term.

On examination, her weight and length were $5.1 \mathrm{~kg}$ and $53 \mathrm{~cm}$, respectively (below the fifth centile for age and sex) in keeping with failure to thrive. She had a high and broad forehead; epicanthic folds; thin, arched, and wide-spaced eyebrows; a small and upturned nose; a long and shallow philtrum; and a thick lower lip, low-set ears, and small mouth
(-Fig. 3). Bilateral fifth toe hypoplasia, toe angulation deformities, broad hands and feet, bilateral clubbed fingers, and loose skin were seen. She had pectus excavatum. Cardiovascular examination revealed loud systolic cardiac murmurs.

MRI of the brain and spinal cord was grossly normal. ECHO showed a persistent left superior vena cava (PLSVC) draining into the coronary sinus with mild pulmonary hypertension.

In both cases, the screening for toxoplasmosis, rubella, cytomegalovirus, herpes simplex virus, human immunodeficiency virus, syphilis, and hepatitis B and $C$ infections were negative. Work-up for inherited metabolic and mitochondrial diseases was negative.

\section{Discussion}

One of the most common anomalies attributed to VPA exposure is neural tube defects (NTDs), which were reported up to $5 \%{ }^{3,4}$ However, none of our case series had spine defects. These findings were in agreement with a previous study with no NTDs in their cases. ${ }^{5}$ Cardiac malformations are commonly reported in FVS, ${ }^{6}$ which were also observed in both our cases. Interestingly, one of our infants had PLSVC, whose association with FVS was not described in any literature. Musculoskeletal abnormalities have recently been highlighted in relation to VPA exposure. ${ }^{7}$ From our case series, one had camptodactyly and clubbed feet, and another one had toe angulation deformities and clubbed fingers.

A recent report demonstrated that the risks of major birth anomalies are not only influenced by a certain type of antiepileptic drug but also by its dose. ${ }^{8}$ Higher malformation rates were seen in those mothers taking $1,500 \mathrm{mg}$ or more

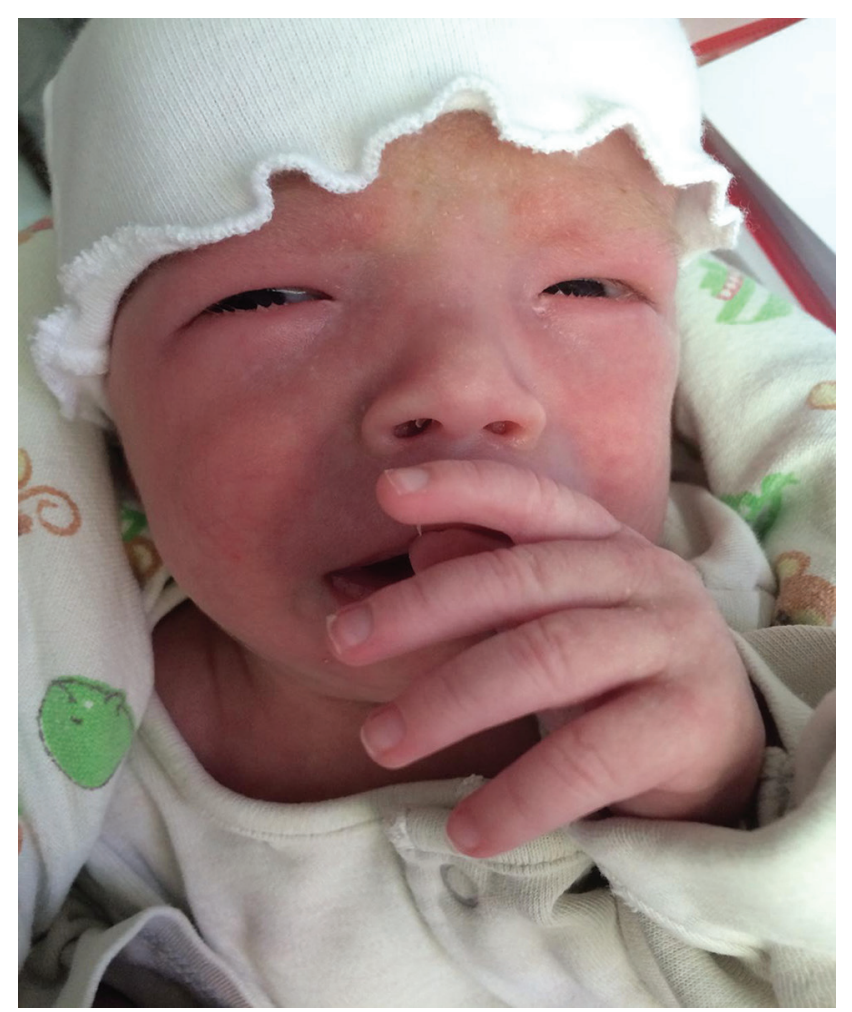

Fig. 3 Dysmorphic features of the second case. 
per day. ${ }^{8}$ A daily dose of less than $700 \mathrm{mg}$ seemed to be of a similar risk compared with other antiepileptic drugs; however, the authors could not draw a conclusion that this could be a safer dose. Cutoff values to determine higher risks were reported in several studies ranging from 600 to $1,500 \mathrm{mg}$ daily. Our last case showed that FVS could occur even at a relatively lower dose (800 $\mathrm{mg}$ per day). Mutlu-Albayrak et al reported FVS cases at as low as $500 \mathrm{mg}$ a day. ${ }^{7}$

Genetic susceptibility to VPA exposure is linked to FVS, which could explain why only certain groups of children are affected. This may include the underlying genetic polymorphism influencing the drug metabolism in both the mother and fetus. This hereditary susceptibility theory is strengthened by a report of FVS in three sets of siblings. ${ }^{5}$ VPA, as a direct inhibitor of histone deacetylase, was found to induce epigenetic modifications. ${ }^{9}$ Long-term use of VPA, in addition to genetic fetal susceptibility may help propagate the cascade of VPA teratogenicity. This phenomenon was observed in all mothers taking VPA more than 10 years. ${ }^{7}$ Our first case took VPA for 11 years, and the second one took it for nearly 15 years.

The role of folate supplementation in preventing FVS remains debatable. In both our cases, FVS occurred despite compliance with folate. The UK registry showed that the rates of major congenital defects in mothers taking antiepileptics on folate were as high as in those on antiepileptic drugs without folate. ${ }^{10}$ However, these findings did not oppose to the common recommendation of folate use in the pregnant women.

In conclusion, FVS can occur at different doses of VPA. We found PLSVC in one of our cases, which has not been described previously in association with FVS. Meticulous ultrasound examination is crucial during antenatal follow-up for screening of congenital anomalies in pregnant mothers on antiepileptic drugs.

Key Messages: Fetal valproate syndrome can occur at any dose of valproate exposure during pregnancy. Meticulous ultrasound examination is crucial during the antenatal follow-up for screening of congenital anomalies in those mothers taking valproate.
Funding

None.

\section{Conflict of Interest}

None declared.

\section{References}

1 Owens MJ, Nemeroff CB. Pharmacology of valproate. Psychopharmacol Bull 2003;37(Suppl 2):17-24

2 Kinsner-Ovaskainen A, Lanzoni M, Garne E, et al. A sustainable solution for the activities of the European network for surveillance of congenital anomalies: EUROCAT as part of the EU Platform on Rare Diseases Registration. Eur J Med Genet 2018;61(9):513-517

3 Bjerkedal T, Czeizel A, Goujard J, et al. Valproic acid and spina bifida. Lancet 1982;2(8307):1096

4 Wyszynski DF, Nambisan M, Surve T, Alsdorf RM, Smith CR, Holmes LB; Antiepileptic Drug Pregnancy Registry. Increased rate of major malformations in offspring exposed to valproate during pregnancy. Neurology 2005;64(6):961-965

5 Malm H, Kajantie E, Kivirikko S, Kääriäinen H, Peippo M, Somer M. Valproate embryopathy in three sets of siblings: further proof of hereditary susceptibility. Neurology 2002;59(4):630-633

6 Jentink J, Loane MA, Dolk H, et al; EUROCAT Antiepileptic Study Working Group. Valproic acid monotherapy in pregnancy and major congenital malformations. N Engl J Med 2010;362(23):2185-2193

7 Mutlu-Albayrak H, Bulut C, Çaksen H. Fetal valproate syndrome. Pediatr Neonatol 2017;58(2):158-164

8 Tomson T, Battino D, Bonizzoni E, et al; EURAP study group. Dose-dependent risk of malformations with antiepileptic drugs: an analysis of data from the EURAP epilepsy and pregnancy registry. Lancet Neurol 2011;10(7):609-617

9 Tung EW, Winn LM. Epigenetic modifications in valproic acid-induced teratogenesis. Toxicol Appl Pharmacol 2010;248(3):201-209

10 Morrow JI, Hunt SJ, Russell AJ, et al. Folic acid use and major congenital malformations in offspring of women with epilepsy: a prospective study from the UK Epilepsy and Pregnancy Register. J Neurol Neurosurg Psychiatry 2009;80(5):506-511 